\title{
The effect of smartphone use on neck flexion angle and hand grip power among adolescents: Cross-sectional study
}

\author{
TAMER M. SHOUSHA ${ }^{1,2}$, HAMADA AHMED HAMADA 34 , NEHAD A. ABO-ZAID ${ }^{4}$, MOHAMED Y. \\ ABDELHAMID ABDELSAMEE ${ }^{5}$, MOHAMED A. BEHIRY ${ }^{6}$ \\ ${ }^{1}$ Department of Physiotherapy, CHS, University of Sharjah, United Arab Emirates \\ ${ }^{2}$ Department of Physical Therapy for Musculoskeletal Disorders and its Surgery, Faculty of Physical Therapy, Cairo \\ University, Egypt \\ ${ }^{3}$ Department of Biomechanics, Faculty of Physical Therapy, Cairo University, Egypt \\ ${ }^{4}$ Department of Physical Therapy for Paediatrics, Faculty of Physical Therapy, South Valley University, Qena, Egypt \\ ${ }^{5}$ Department of Basic Science, Faculty of Physical Therapy, Delta University for Science and Technology, Egypt \\ ${ }^{6}$ Department of Orthopaedics, Faculty of Physical Therapy, Delta University for Science and Technology, Egypt
}

\begin{abstract}
Background: The use of smart phones has become increasingly popular and almost indispensable in contemporary life, but many studies have addressed that excessive use negatively affects the various developmental domains. Purpose: The purpose of this study was to examine the effect of prolonged smartphone use on the forward neck translation, neck flexion angle and handgrip power for duration of 8 weeks. Materials and Methods: Ninety students from nine different international schools in Sharjah, UAE, with age ranging between 13-17 years. Participated in this study. Subjects were divided into two groups based on their daily frequency of smartphone use. Group (I) using smart phones less than 4 hours/day and Group (II) using more than 4 hours/day. The Neck flexion angle and forward neck translation were measured by the posture assessment mobile application (PostureCo, Inc), during their normal straight upright postural standing position. Handgrip power was measured with a Handheld Dynamometer (HHD) for both dominant and non-dominant hands, with arms abducted 30 degrees and wrist slightly extended (10 degrees). Measures were repeated 3 times and the average was considered for data analysis. Results: After 8 weeks of smart phone usage, statistical analyses revealed significant increase and decrease in the forward neck translation and neck flexion angles respectively. On the other hand, there were no statistically significant differences in handgrip power in both groups. Conclusion: Our results revealed the significant effect of the prolonged use of smartphones on the neck flexion angle, forward head translation without affecting handgrip power.
\end{abstract}

Keywords: Smart phone; Neck flexion angle; Forward head translation; Hand grip power.

\section{Cite this article as:}

Shousha, T.M., Hamada, H.A., Abo-Zaid, N.A., Abdelsamee, M.Y.A., \& Behiry, M.A. (2021). The effect of smartphone use on neck flexion angle and hand grip power among adolescents: Cross-sectional study. Journal of Human Sport and Exercise, 16(3proc), S883-S891. https://doi.org/10.14198/jhse.2021.16.Proc3.05

Corresponding author. Department of Biomechanics, Faculty of Physical Therapy, Cairo University, Egypt.

E-mail: hamada.ahmed@pt.cu.edu.eg

Abstract submitted to: Winter Conferences of Sports Science. Costa Blanca Sports Science Events, 22-23 March 2021. Alicante, Spain.

JOURNAL OF HUMAN SPORT \& EXERCISE ISSN 1988-5202.

(c) Faculty of Education. University of Alicante.

doi:10.14198/jhse.2021.16.Proc3.05 


\section{INTRODUCTION}

Adolescents spend prolonged time using their smartphones due to frequent visiting of social media sites (Attila, 2015), so they are more susceptible to negative effects of smartphone use due to their receptive and easily adaptiveness to new technologies. In addition, they are highly sensitive to the effect of their peers and environment (Jo, Na \& Kim, 2017). Twenty-six percent of adolescents support spending more than 8 hours / day using screen media (Domoff et al., 2019). The incidence of problems in adolescence with overuse smartphone ranged from $5 \%$ (Lopez-Fernandez, 2015) up to 50\% (Yen, et al., 2009) with a higher incidence in younger adolescents than older adolescents (Lopez-Fernandez, 2014). The use of smartphones has been gradually increasing throughout the years due to a variety of factors. Some of which are the different brands of smartphones with attracting capabilities, as well as to the various social media applications. Moreover, game applications get people addicted to their phones without being aware of the consequences their body and posture deformities, as well as psychosocial problems (Arslan, 2013). This may predispose to musculoskeletal abnormalities including forward neck posture, hyper lordosis and increased neck and upper extremity pain (Lee, 2015).

The adolescents are also vulnerable to smartphone addiction (Jo, Na \& Kim, 2017). This addiction resulting from overuse has negative impact on their emotions, behaviours, social communications, academic achievement, and conflicts with family members (Attila, 2015). As the adolescence is a critical duration for brain development, the overuse of smartphones in this period has inhibitory effects on functional connectivity in the anterior insula and the primary motor cortex (Kim, Kim, \& Pyeon, 2016).

A new medical term 'Text Neck' is now applied to the harmful and dangerous condition resulting from extensive and long-term use of mobile phones (Neupane, Ifthikar \& Mathew, 2017). This condition is known to be affecting majority of mobile phone users and is also considered as an amplifying sharp global burden, affecting population of both sex and all the age groups belonging to every society (Samani et al., 2018).

The excessive use of smartphones eventually produces considerable stress on the cervical spine and therefore cause neck pain (Kim \& Kim, 2015). Individuals who are constantly using their smartphones may experience a dramatic decrease in the amount of time they can spare for other social relations, especially activities that involve face to face interactions (Lee et al., 2015). Moreover, it can lead to somatic psychosocial problems reported include complaints such as anxiety, insomnia, depression, psychological distress, and unhealthy lifestyle (Seong-Soo \& Bo-Kyung, 2018).

On the other hand, poor posture while looking at the visual display terminals of smartphones for extended periods causes musculoskeletal problems (Kim \& Kim, 2015; Lee, 2015; Seong-Soo, \& Bo-Kyung, 2018). Visual display terminals of a tablet or cell phone have smaller screens than that of a regular desktop computer, requiring the users to bend his/her neck more, thereby increasing the activity of the neck and shoulder muscles.

The angle at which someone looks at a visual display terminal with a small screen is significantly lower than that of a big screen (Lee, 2016). The average cervical flexion angle is 38.5 degrees when watching a digital multimedia broadcasting phone, and this cervical flexion posture increases the muscle activity of the upper trapezius and splenius capitis muscles compared to a cervical neutral position (Yoo, 2008).

Other side effects of smartphone overuse include enlargement of the median nerve, causing pain in the thumb, decreasing pinch strength and hand function, and significantly higher median nerve cross sectional 
areas were observed in the dominant hands of the high smartphone users than in the non-dominant hands (INal, 2015).

On the other hand, it was reported that there was no difference in the hand muscles' fatigue levels between both genders, and it was recommended that further research studies need to compare between using different brands of mobiles to understand the appropriateness of the design of the phone itself (Sharan \& Ajeesh, 2012).

As previous studies focused on the musculoskeletal hazards of smart phone use but did not consider the longevity of usage, therefore the purpose of this study was to measure the effect of prolonged smartphone use on neck flexion angle and hand grip power. We hypothesized that prolonged smartphone use will have an effect on the forward neck translation, the neck flexion angle and hand grip power after a duration of 8 weeks.

\section{MATERIALS AND METHODS}

\section{Study design}

A cross-sectional study was conducted on adolescent students during the period from March 2020 to January 2021. Informed consents were signed by the parent or guardian of each participant. Verbal assent was obtained from each participant in the presence of the parent or legal guardian as well. Procedures of our study had No: REC-18-02-26-02-S approved by the Institutional Ethical Committee Clearance of University of Sharjah, and also it was registered on Clinicaltrial.gov and the registration number was NCT04715009 that was registered on Clinicaltrial.gov.

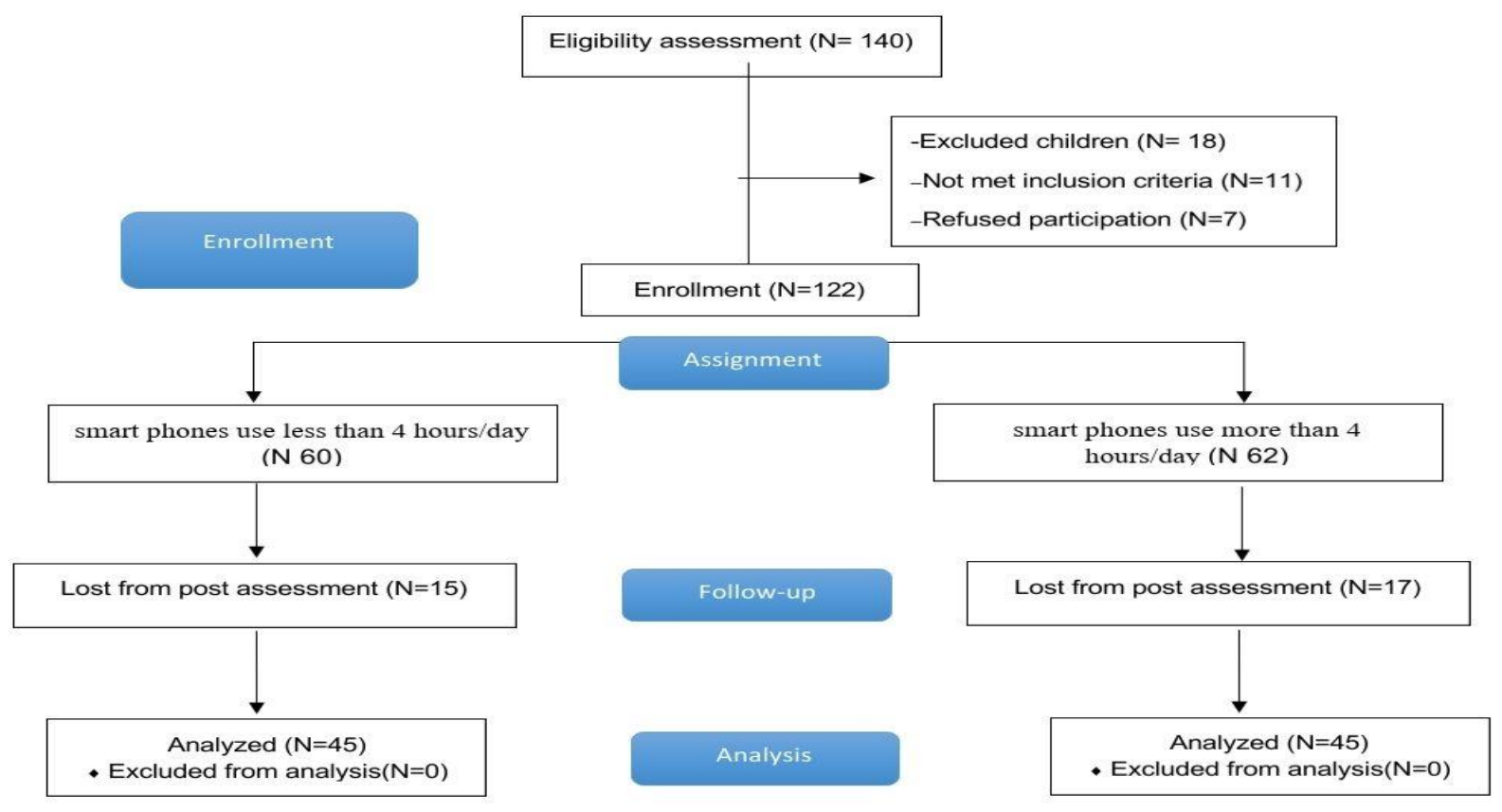

Figure 1. Flowchart of the study. 


\section{Study population}

A convenient sample of ninety male and female students from 9 different international schools between 13 to 17 years of age were recruited for this study. Participants were free from any musculoskeletal or neurological pathologies. They all reported the use of smartphones with nearly the same dimensions and weight including iPhone 8 plus, [158.4 mm in height and 78.1 in width] and Samsung note 6-7 [153mm in height, and $74.5 \mathrm{~mm}$ in width]. Participants were excluded if they suffered from any previous or current neurologic problems, spinal deformities or had a history of neck, or upper extremity surgery.

The participants were divided into two groups based on using their mobile phone for either more than or less than 4 hours every day (Samaan et al., 2018) (flowchart Figure 1). This information was obtained as the participants filled a Smartphone Usage questionnaire (Appendix 1). The assessment was performed by an experienced physical therapist at base line and after 8 weeks.

\section{Outcome measures}

With regards to the hand grip Power, participants were asked to stand upright having their arms $30^{\circ}$ abducted and wrist $10^{\circ}$ extended, holding the dynamometer and gripping it with their most strength upon full exhalation. Measurement was repeated three times and the average was taken for both the dominant and non-dominant hands (Levangie \& Norkin, 2005). Next, participants stood with their backs to the wall. They were asked to stand straight according to their normal relaxed forward-facing position. The posture assessment mobile application was used to measure the neck flexion angle and forward neck translation (Lee, Lee, \& Park, 2015) (fig 2). The higher the neck flexion angle, the more neutral the head position is, the lower the neck flexion angle the more the subject has a relaxed non-neutral position (Hansraj, 2014). These measurements were taken on two successive occasions, at baseline and at the end of 8 weeks' time.

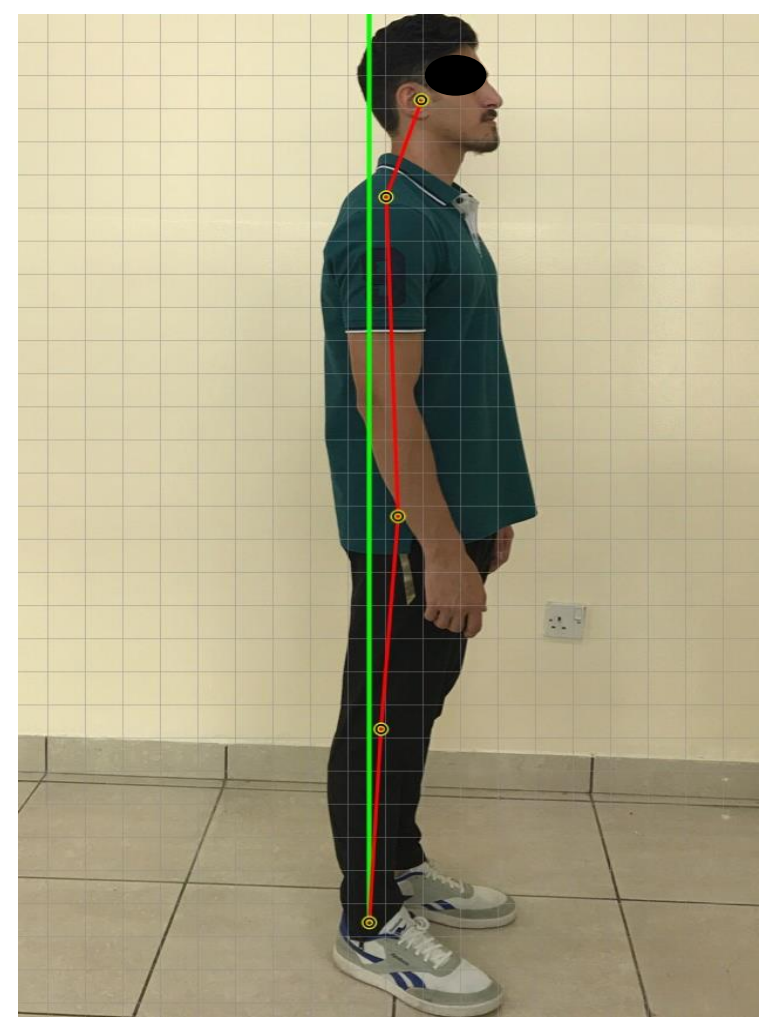

Figure 2. The posture assessment mobile application. 


\section{RESULTS}

\section{Statistical power analysis}

The sample size for this study was calculated using the $G^{*}$ power program 3.1.9 (G power program version 3.1, Heinrich-Heine-University, Düsseldorf, Germany). Sample size calculation based on $F$ tests (ANOVA: Fixed effects, omnibus, one-way), Type I error $(\alpha)=.05$, power (1-a error probability) $=.80$, and effect size $f$ $(V)=0.260$ with 2 independent groups comparison for 4 major variable outcomes. The appropriate minimum sample size for this study was 120 patients (60 patients in each group as a minimum).

The SPSS for windows version 22 was used to analyse the data. One-way ANOVA test was used to assess differences within and between groups regarding forward head translation, neck flexion angle and hand grip power. As presented in Table 1, there was no significant difference $(p>.05)$ between groups with regards to age, weight, height, gender distribution or hand dominance.

Table 1. General characteristics of the two studied groups.

\begin{tabular}{|c|c|c|c|c|}
\hline & Group $A(n=45)$ & \multicolumn{2}{|c|}{ Group B $(n=45)$} & $p$-value \\
\hline Age (years.) & $15.13 \pm 1.01$ & \multicolumn{2}{|c|}{$16.47 \pm 0.68$} & $.120(\mathrm{NS})$ \\
\hline Weight (kg.) & $54.64 \pm 2.43$ & \multicolumn{2}{|c|}{$57.25 \pm 1.1$} & .231 (NS) \\
\hline Height (cm) & $165.30 \pm 6.82$ & \multicolumn{2}{|c|}{$166.14 \pm 7.65$} & .161 (NS) \\
\hline \multicolumn{5}{|l|}{ Gender } \\
\hline $\begin{array}{l}\text { Male } \\
\text { Female }\end{array}$ & $\begin{array}{l}22(73.3 \%) \\
8(26.7 \%)\end{array}$ & $\begin{array}{l}20(66.7 \%) \\
10(33.3 \%)\end{array}$ & $\chi^{2}=0.317$ & $.563(\mathrm{NS})$ \\
\hline \multicolumn{5}{|l|}{ Dominance } \\
\hline $\begin{array}{l}\text { Right } \\
\text { Left }\end{array}$ & $\begin{array}{l}21(70.0 \%) \\
7(23.33 \%)\end{array}$ & $\begin{array}{c}9(30 \%) \\
23(76.66 \%)\end{array}$ & $\chi^{2}=0.218$ & .641 (NS) \\
\hline
\end{tabular}

Data are expressed as mean \pm SD or number $(\%) \cdot \chi^{2}=$ Chi square test. $N S=p>.05=$ not significant.

As presented in Table 2, there was a significant difference $(p<.05)$ between groups regarding usage hours per day.

Table 2. Comparison between values of average time of smartphone use in the two studied groups.

\begin{tabular}{lcccc} 
Duration of smartphone use/day (hrs.) & Group $A(n=30)$ & Group $B(n=30)$ & $Z$ value & $p$-value \\
\cline { 2 - 5 } & $6.37 \pm 0.98$ & $3.62 \pm 2.26$ & -6.413 & $.001^{*}$ \\
\hline
\end{tabular}

Data are expressed as mean \pm SD. Z value $=$ Mann-Whitney test, ${ }^{*}$ Significant $p<.05$.

Results did not reveal any statistical difference for the hand power of both sides as shown in table (3). On the other hand, regarding forward head translation, within group comparisons showed a statistically significant difference for both groups post 8 weeks of smartphone use represented as $p=.001$ and $p=.003$ respectively. Similarly, between groups comparisons revealed a statistically significant difference post 8 weeks of smartphone represented as $p=.001$ (Table 3 ).

Regarding neck flexion angle, within group comparisons showed a statistically significant difference for both groups post 8 weeks of smartphone use represented as $p=.001$ and $p=.001$ respectively. Similarly, between 
groups comparisons revealed a statistically significant difference post 8 weeks of smartphone represented as $p=.041$ (Table 3).

Table 3. ANOVA analysis for hand power, forward neck translation and neck flexion angle in both groups at baseline and post 8 weeks of smart phone use.

\begin{tabular}{llccc}
\hline Dependent Variable & & Group A (Mean \pm SD) & Group B (Mean \pm SD) & $p$-value \\
\hline \multirow{4}{*}{ Right Hand power } & Base line & $34.4 \pm 4.3$ & $31.6 \pm 6.1$ & .681 \\
& Post 8 weeks & $35.7 \pm 5.2$ & $32.1 \pm 7.4$ & .543 \\
& $p$-value & .548 & .510 & \\
Left Hand power & Base line & $30.6 \pm 8.1$ & $32.8 \pm 6.1$ & .716 \\
& Post 8 weeks & $31.4 \pm 6.1$ & $34.8 \pm 2.1$ & .680 \\
& p-value & .811 & .698 & \\
Forward neck translation & Base line & $5.9 \pm 1.6$ & $5.1 \pm 1.5$ & $.033^{*}$ \\
& Post 8 weeks & $7.2 \pm 2.6$ & $6.4 \pm 1.4$ & $.001^{*}$ \\
& $p$-value & $.001^{*}$ & $.003^{*}$ & \\
Neck flexion angle & Base line & $61.4 \pm 4.6$ & $66.9 \pm 6.6$ & $.027^{*}$ \\
& Post 8 weeks & $56.1 \pm 7.8$ & $59.6 \pm 5.6$ & $.041^{*}$ \\
& $p$-value & $.001^{*}$ & $.001^{*}$ & \\
\hline
\end{tabular}

\section{DISCUSSIONS AND CONCLUSIONS}

The purpose of this study was to examine the effect of prolonged smartphone use on forward neck translation, neck flexion angle and handgrip power after duration of 8 weeks.

Smart phone is one of the fastest growing technological developments of all times and becoming an integral part of daily life among adolescents. Frequent use of smartphones forces the users to adopt an awkward posture to increased risk of musculoskeletal problems.

The use of smartphones in an incorrect manner and wrong postural alignment usually causes neck pain, back pain, and other musculoskeletal issues (Lee, 2015). In this study, the participants used their phone for either more than or less than 4 hours every day. The handgrip power, neck flexion angle and forward head translation were assessed at baseline and after 8 weeks. After 8 weeks of smart phone usage, statistical analysis revealed significant increase and decrease in the forward neck translation and neck flexion angles respectively without affecting handgrip power.

Our findings suggest that smartphones have a direct effect on the flexion angle of the cervical spine and the forward head posture. This came in agreement with several studies revealing significant musculoskeletal defects and increased musculoskeletal activity rates which could cause fatigue on the longer term (Yoo, 2008; Sharan \& Ajeesh, 2012; Lee, Lee, \& Park, 2015; Lee, 2016). In addition, some have even shown neurological deficits, and enlarged median nerve accompanied by hand pain (INal, Demírcl, Çetintürk, Akgönül \& Savaş, 2015).

Janwantanakul, Sitthipornvorakul \& Paksaichol, 2012 \& Hansraj, 2014 concluded that, loss of normal curvatures of the spine were resulting from increasing the bending of the head in forward position at varying degrees which leads to substantial increase of stress towards the cervical spine. 
The finding of the study supports the findings of Hakala et al. 2006 who confirmed that prolonged smartphone use increases the risk of neck-shoulder pain in adolescents, as well as Kim, Kim \& Pyeon, 2015, reporting that frequent smartphone use provides neck and shoulder discomfort.

Our results clearly point to the fact that consequences of smart phone use including increased forward neck translation and decreased neck flexion angle may be strongly correlated with other disorders directly affected by the head and neck position as tension type headaches (Sharan \& Ajeesh, 2012).

\section{Limitations}

The sample size was limited based on the current Covid-19 pandemic and related social distancing and restrictions. Also, the duration of usage was assumed based on the subjective responses of the participants without any means to control the time of usage.

\section{ACKNOWLEDGMENTS}

The authors would like to thank all participants in the current study.

\section{REFERENCES}

Arslan, A. (2013). Examination of cell phone usage habits and purposes of education faculty students. International Journal of Human Sciences; 20(2):240-246.

Attila Körmendi (2015). Smartphone usage among adolescents. Psychiatr Hung; 30(3):297-302.

Domoff, SE, Foley, RP, Ferkel, R. Addictive phone use and academic performance in adolescents. Hum Behav \& Emerg Tech. 2020; 2: 33- 38. https://doi.org/10.1002/hbe2.171

Fernández-de-las-Peñas, C., Alonso-Blanco, C., Cuadrado, M.L., et al. (2005). Forward head posture and neck mobility in chronic tension-type headache: a blinded, controlled study. Cephalalgia. Mar; 26(3):314-9. https://doi.org/10.1111/j.1468-2982.2005.01042.x

Hakala, P.T., Rimpelä, A.H., Saarni, L.A., \& Salminen, J.J. (2006). Frequent computer-related activities increase the risk of neck-shoulder and low back pain in adolescents. The European Journal of Public Health; 16, 536-541. https://doi.org/10.1093/eurpub/ckl025

Hansraj, K.K. (2014). Assessment of stresses in the cervical spine caused by posture and position of the head. Surgical Technology International; 25: 277-9.

INal, E., Demircl, k., Çetintürk, A., Akgönül, M. \& Savaş, S. (2015). Effects of smartphone overuse on hand function, pinch strength, and the median nerve. Muscle \& Nerve; 52(2), pp.183-188. https://doi.org/10.1002/mus.24695

Janwantanakul, P., Sitthipornvorakul, E., Paksaichol, A. (2012). Risk factors for the onset of nonspecific low back pain in office workers: a systematic review of prospective cohort studies. J Manipulative Physiol Ther; 35: 568-577. https://doi.org/10.1016/i.jmpt.2012.07.008

Jo, H.S., Na, E., \& Kim, D.J. (2017). The relationship between smartphone addiction predisposition and impulsivity among Korean smartphone users. Addict Res Theory, 26: 77-84. https://doi.org/10.1080/16066359.2017.1312356

Kim, D.J., Kim, J.Y., \& Pyeon, A. (2016). Altered functional connectivity related smartphone overuse in adolescent. Int J Neuropsychopharmacol; 19: 9; Pubmed Central PMCID: PMC5616242. PM306. https://doi.org/10.1093/inp/pyw041.306

Kim, H.J. \& Kim, J.S. (2015). The relationship between smartphone use and subjective musculoskeletal symptoms and university students. J Phys Ther Sci; 27(3): 575-9. https://doi.org/10.1589/jpts.27.575 
Lee, H. (2016). Neck Pain and Functioning in Daily Activities Associated with Smartphone Usage. The Journal of Korean Physical Therapy, 28(3), 183-188. https://doi.org/10.18857/jkpt.2016.28.3.183

Lee, M., Hong, Y., Lee, S., Won, J., Yang, J., Park, S., Chang, K. \& Hong, Y. (2015). The effects of smartphone use on upper extremity muscle activity and pain threshold. Journal of Physical Therapy Science; 27(6), pp.1743-1745. https://doi.org/10.1589/jpts.27.1743

Lee, S., Lee, D. \& Park, J. (2015). Effect of the cervical flexion angle during smart phone use on muscle fatigue of the cervical erector spinae and upper trapezius. Journal of Physical Therapy Science; 27(6), pp.1847-1849. https://doi.org/10.1589/jpts.27.1847

Levangie, P. \& Norkin, C. (2005). Joint structure and function. 4th ed., Davis Company. Elseavier, 156164.

Lopez-Fernandez, O. (2015). Problem mobile phone use in Spanish and British adolescents: First steps towards a cross-cultural research in Europe. In: Riva G, Wiederhold BK, Cipresso P, editors. Identity and relationships in online communities. The psychology of social networking, Vol. 2. Warsaw: De Gruyter; pp. 186-201. https://doi.org/10.1515/9783110473858-015

Lopez-Fernandez, O., Honrubia-Serrano, L., Freixa-Blanxart, M., \& Gibson, W. (2014). Prevalence of problematic mobile phone use in British adolescents. Cyberpsychol Behav Soc Netw;17(2):91-8. https://doi.org/10.1089/cyber.2012.0260

Marina, N.S., Emam, H.E., Ahmed, M.E., Amena, S.H. (2018). Effect of prolonged smartphone use on cervical spine and hand grip strength in adolescence. Volume 5 Issue 9; September; Page No. 49 53.

Neupane, S., Ifthikar Ali, U.T., \& Mathew, A. (2017). Text-Neck Syndrome-Systemic review. Imperial Journal of Interdisciplinary Research; 3(7):141-148.

Samani, P., Athaval, N., Shyam, A., \& Sancheti, P. (2018). Awareness of text neck syndrome in youngadult population. International Journal of Community Medicine and Public Health; 5(8). https://doi.org/10.18203/2394-6040.ijcmph20183057

Seong-Soo, C. \& Bo-Kyung, S. (2018). Smartphone use and smartphone addiction in middle school students in Korea: Prevalence, social networking service, and game use. Health Psychology Open. https://doi.org/10.1177/2055102918755046

Sharan, D. \& Ajeesh, P. (2012). Risk factors and clinical features of text message injuries. https://doi.org/10.3233/WOR-2012-0294-1145

Yen, C.F., Tang, T.C., Yen, J.Y., Lin, H.C., Huang, C.F., Liu, S.C., et al. (2009). Symptoms of problematic cellular phone use, functional impairment and its association with depression among adolescents in Southern Taiwan. J Adolesc; 32(4):863-73. https://doi.org/10.1016/j.adolescence.2008.10.006

Yoo, C.U. (2008). Electromyographic activity of the neck and shoulder muscles while watching a DMB phone with the neck flexed. Yonsei University, dissertation of master's degree.

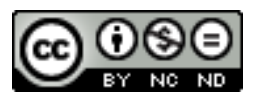

This work is licensed under a Attribution-NonCommercial-NoDerivatives 4.0 International (CC BY-NC-ND 4.0). 


\section{APPENDIX 1. Smartphone Usage questionnaire.}

\section{SMART PHONE USAGE AND NECK FLEXION ANGLE WITH HAND GRIP}

Thank you for taking the time to participate in this survey

\begin{tabular}{|c|c|c|c|c|c|c|}
\hline \multicolumn{7}{|l|}{ Statement } \\
\hline \multicolumn{7}{|l|}{ History of neck pain } \\
\hline How often you experienced neck pain last 6 months? & Not at all & Once & \multicolumn{2}{|c|}{ Monthly } & Weekly & daily \\
\hline Rate the average intensity of neck pain last 6 months & Very mild & Mild & \multicolumn{2}{|c|}{$\begin{array}{c}\text { Moderat } \\
\mathrm{e}\end{array}$} & Severe & Very severe \\
\hline Have you been seen by a Chiropractor last 6 months for neck pain? & \multicolumn{3}{|c|}{ Yes } & \multicolumn{3}{|c|}{ No } \\
\hline \multicolumn{7}{|l|}{ If yes specify the number of visit last 6 months } \\
\hline Have you taken pain killers last 6 months for neck pain & \multicolumn{4}{|c|}{ Yes } & \multicolumn{2}{|r|}{ No } \\
\hline Have you done cervical surgery? If yes, what year? & \multicolumn{3}{|c|}{ Yes, Year: } & & \multicolumn{2}{|r|}{ No } \\
\hline Do you have arthritis (joint inflammation) of neck or spin? & \multicolumn{3}{|c|}{ Yes } & & \multicolumn{2}{|r|}{ No } \\
\hline \multicolumn{7}{|l|}{ Smart Phone Usage } \\
\hline What type of smartphone you use? & iPhone & Samsung & \multicolumn{2}{|c|}{ Motorola } & \multicolumn{2}{|c|}{ Other: } \\
\hline How much time you operate your phone daily? & $0-30 \mathrm{~min}$ & $\begin{array}{c}>30 \mathrm{mi} \\
\mathrm{n} \\
- \\
1 \text { hour }\end{array}$ & & & $\begin{array}{l}>2-4 \\
\text { hours }\end{array}$ & $>4$ hours \\
\hline \multirow[t]{2}{*}{ What is the most common use for your smartphone? } & Call & Texting & \multicolumn{2}{|c|}{$\begin{array}{l}\text { Reading } \\
\text { (article or } \\
\text { e-book) }\end{array}$} & E-mail & Social Media \\
\hline & $\begin{array}{l}\text { Playing } \\
\text { Games }\end{array}$ & \multicolumn{2}{|c|}{$\begin{array}{l}\text { Watching } \\
\text { Videos }\end{array}$} & \multicolumn{2}{|c|}{$\begin{array}{c}\text { Capture Photos } \\
\text { or Videos }\end{array}$} & $\begin{array}{l}\text { Listening to } \\
\text { audio hands free }\end{array}$ \\
\hline \multirow[t]{2}{*}{ What is the second most common use for your smartphone? } & Call & Texting & \multicolumn{2}{|c|}{$\begin{array}{l}\text { Reading } \\
\text { (article or } \\
\text { e-book) }\end{array}$} & E-mail & Social Media \\
\hline & $\begin{array}{l}\text { Playing } \\
\text { Games }\end{array}$ & \multicolumn{2}{|c|}{$\begin{array}{l}\text { Watching } \\
\text { Videos }\end{array}$} & \multicolumn{2}{|c|}{$\begin{array}{c}\text { Capture Photos } \\
\text { or Videos }\end{array}$} & $\begin{array}{l}\text { Listening to } \\
\text { audio hands free }\end{array}$ \\
\hline \multirow[t]{2}{*}{ What is the third most common use for your smartphone? } & Call & Texting & \multicolumn{2}{|c|}{$\begin{array}{l}\text { Reading } \\
\text { (article or } \\
\text { e-book) }\end{array}$} & E-mail & Social Media \\
\hline & $\begin{array}{l}\text { Playing } \\
\text { Games }\end{array}$ & \multicolumn{2}{|c|}{$\begin{array}{l}\text { Watching } \\
\text { Videos }\end{array}$} & \multicolumn{2}{|c|}{$\begin{array}{c}\text { Capture Photos } \\
\text { or Videos }\end{array}$} & $\begin{array}{l}\text { Listening to } \\
\text { audio hands free }\end{array}$ \\
\hline
\end{tabular}

\section{(c) $(7) \odot$}

This work is licensed under a Attribution-NonCommercial-NoDerivatives 4.0 International (CC BY-NC-ND 4.0). 